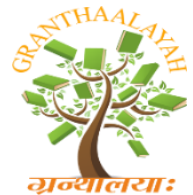

\author{
INTERNATIONAL JOURNAL OF RF
GRANTHAALAYAH \\ A knowledge Repository
}

Science

\title{
THE FIGHT OF PATIENT WITH PARANOID SCHIZOPHRENIA DISORDER WITH HIS THE PSYCHIATRIC DIAGNOSIS: A GAME OF "EVERYTHING OR NOTHING"
}

\author{
Simona Trifu ${ }^{* 1}$, Alexandra Popescu ${ }^{2}$, Ana Miruna Dragoi ${ }^{3}$ \\ *1 University of Medicine and Pharmacy "Carol Davila", Bucharest, Romania \\ ${ }^{2,3}$ Hospital for Psychiatry “Alex. Obregia”, Bucharest, Romania
}

\begin{abstract}
Introduction: "Blue whale challenge" is a large social media phenomenon believed to have originated in Russia in 2015. It is supposed to be a "game" in which the "player" receives 50 tasks from an online administrator. Initial tasks are more inclined towards self-harm and antisocial behavior, the final task being suicide. The name is thought to be derived from "failed whales" that suggest suicide.

Motivation: Although the target audience of this outrages game is mainly adolescents; it has proven to be eminently more harmful among psychiatric patients, of all ages, especially those with psychotic disorders. When psychosis overlaps with an already dangerous online "game", the risks are heightened.

Objectives: Our case study intends to highlight the risks of a 35-year-old patient, a former police officer, diagnosed with paranoid schizophrenia about 15 years ago, difficult to control from therapeutic point of view, which is completely immersed in this "game", in which the tasks are on the border between concrete and delirium.

Methods: Emergency psychiatric hospitalization, medical supervision, daily psychiatric monitoring, psychological evaluation, psychodynamic interview, case study.

Results: The patient deliriously interprets the rules of the game his current task is to go to three different psychiatrists and to prove his health in order to "release" him from his diagnosis of paranoid schizophrenia. He motivates the objective of the challenge with the Blue Whale the "liberation of the soul", the alternative being suicide. He plays "all or nothing", there are no differences in shades between "Beware of donkeys" (children's game), "Blue whale" and "Russian roulette" (games for real men). The patient himself sees either the garbage man who deserves the lethal injection, or Jesus capable of winning the game. His thinking is dominated by the conflict between the concrete and the abstract; the secret of the paranoid patient being the emphatic ability to transform his powerlessness into "I am invincible!", because for this patient "at first it was the word". When he spoke about his previous tasks, he confessed many acts of violence, pseudoreminiscence with delirious integration in the form of confabulations. In addition, he believes that everyone receives orders from the Blue Whale, including medical staff, which makes difficult to establish a doctor-patient relationship.
\end{abstract}


Keywords: Cybercrime; Paranoid Schizophrenia; Delusional Interpretability; Xenopathic Control; Suicide Risk; Homicide Risk; Impulsive-Unpredictable Behavior.

Cite This Article: Simona Trifu, Alexandra Popescu, and Ana Miruna Dragoi. (2019). "THE FIGHT OF PATIENT WITH PARANOID SCHIZOPHRENIA DISORDER WITH HIS THE PSYCHIATRIC DIAGNOSIS: A GAME OF "EVERYTHING OR NOTHING"." International Journal of Research - Granthaalayah, 7(11), 240-248. 10.29121/granthaalayah.v7.i11.2020.362.

\section{Introduction}

\subsection{Family History}

He comes from a complete family:

- about his father: sailor as profession, described as "a tolerant, Transylvanian man", "an anchor" (symbolic from the metaphorical plane: sailor father, pillar of the family).

-a bout his mother: teacher, he says about her that "it is very easy to move from one state to another, even though he is suffering a lot, he can change his mood only by seeing me", "strumpet", has a complete delirium centered on the rape of his mother by various political personalities, suggestive elements for affective investment.

\subsection{Professional History}

He graduated a high school in Bucharest, real profile, having a good school performance, later continued his studies at the Police Academy. He claims that he was discharged from the Police Academy in 2004 because "the disease had begun", but he could be re-registered with a false diagnosis of tuberculosis. After graduating from the Academy, he holds an Officer position in a Police Station, where it has a short evolution, about 4 years, due to mental illness. He also had an unsuccessful attempt to work in a water company but the illness greatly affected the socioeconomic functioning of the patient, who was forced to return to the parental home and to retire with a degree II disability certificate ("I was forced to retire"). Currently he gave up his income "I do not need these moneys, after winning the game with the Blue Whale, I hope I can get the damages from ECHR - European Court of Human Rights."

\subsection{History of the Disease}

He claims possible seizures in childhood, around the age of seven, for which he has been subjected to monthly investigations (Brain CT, Electroencephalogram, Lumbar Points) following a treatment with Prednisone and Carbamazepine - we believe an encephalitis/viral meningitis with convulsive manifestations.

The onset of the disease occurred in 2004; the diagnosis of paranoid schizophrenia came, but later, in an attempt to hide the disease at work. From 2004 till today he had 15-20 hospitalizations. About the last hospitalization he says it was "all for the purpose of the game, for the reassessment of the diagnosis." 


\section{Materials and Methods}

Considering the actual status of the patient, the medical team used the following methods to deal with this case: his emergency psychiatric hospitalization, continuous medical supervision, daily psychiatric monitorization, psychological evaluation, psychodynamic interview with a team of psychiatrists and psychologists, team study of this case

\section{Results and Discussions}

\subsection{Psychic Examination of the Presented Condition}

The patient voluntarily presents at the hospital, is admitted through the Emergency Room

\subsubsection{Observations}

Patient in neat hospital outfit (gown, pajamas), proper hygiene, cooperative, maintains moderate eye contact, mimicry and gesture, the tone of voice alternates depending on the affective state: seriousness and calmness in approaching topics related to his role as a punisher [1], and in terms of interaction with the interviewer, he presents a jovial and open attitude, trying to impress. From temporal a spatial point of view, the patient overlaps the events and places of the past with the present ones.

\subsubsection{Perceptions}

It denies any hallucinations: auditory, visual or at the level of another analyzer, both at this moment and also in the past, his pathology being at each hospitalization in the register of thought.

\subsubsection{Attention}

The patient maintains his attention throughout the entire discussion he is having with the attending physician. He also answers them with interest and focuses on many details in the answers to the questions asked during the interview. It presents spontaneous hyperproxia for certain insignificant details but integrated deliriously. [2]

\subsubsection{Memory}

We encounter non-selective hypermnesia for certain dates, facts and events, consistent with the predominantly sexual and violent themes. It exaggerates the evocations - multiple, tumultuous, involuntary, removes the subject from his preoccupations; [3]

It presents pseudo-reminiscent on which the patient builds confabulations and supports his delirious ideation, dreamlike and fantastic confabulations - on the sadistic and sexual dimension, cryptomnesia "I invented the Blue Whale game". There is a decrease in the capacity of discrimination between personal events (fragments of memories) and foreign events (eg those in the political area). [4] 
Also, from the memory disorders area, we have the reduplication params pick = the patient says that he was once in the same situation (he met with interviewers, reliving the present situation);

\subsubsection{Thinking}

The rhythm of ideas and the speaking fluence is accelerated, the increase of representations, the imagination, the mobility of attention, the affective tone, the logos, the graphs, the graphomania are observed, so a global acceleration of the psychic life.

The logical associations are weakened, the patient slips from the concrete plan to the metaphorical one, with disorganization at the level of the whole discourse and at the level of the phrases circumstantiality: "I will tell you about doctor XX ", the patient revolves around the idea and in the end, he does not score the core of the problem. The disorganized psychotic patient does not know the core of the problem: he has a delirium not so well systematized, escaping the meaning of the problem. It slips from one idea to another pathological ideas, invade the areas of the normal and struggle to prevail. [5]

Qualitative disorders, content, rewriting the present with the delirium of imagination - rich imagination in the creation of the scenes, which give the feeling of unreality, although they are well developed, thus giving a new meaning to the game Blue Whale.

Delirious idea of grandeur, enormity, referential experiences, ideas of invention and reform, with the particularity of the case: "I resist with all the medicines you give me and against them!" - this is a delirious idea of relationship; through the game "he met" various politicians, doctors, high society people. It is also observed the immaturity of magnitude, sustained by magic, in the experience of being subjected to tests that must be overcome and predictions to be fulfilled. [6]

Delirious idea of persecution, prejudice, prosecution: "I was persecuted, hunted, I was admitted voluntarily"

Idea of xenopathic control: everything happens xenopathically, he and the other patients are sent to the hospital through the TV. [7]

Delirium oil stain draws in its story the medical staff, patients from the hospital.

There are phenomena of diffusion of thoughts, but the patient then returns by pointing: "I am the core."

The patient himself brings into the spontaneous discourse the idea of suicide, which can be achieved in several ways:

"To get rid of this life, because I don't like it anymore" = in the depressive dimension

"Because I was very wrong about others" = the melancholy dimension of guilt

"I am a justice and I want justice done!" = Suicide of the paranoiac in the vision "the big world is not good enough for me" 
Ambivalence towards parents

Theory of mind, cognitive deficits in schizophrenia

Notification of coincidences; accusatory synchronicities.

The narcissistic-paranoid idea of "being chosen".

The speech is contaminated by chemical elements (Chlorine, Sodium, Phosphorus) that suggest regression, return to the roots, suggestive for the continuous search for the cause of the paranoid patient's disease: "when I started my sexual life at 18, there was a chemical imbalance in brain". The paranoid tries to negotiate his diagnosis: the patient reports that the game organizers told him "Choose a diagnosis because you did it wrong".

\subsubsection{Language}

It performs through a broad, circumstantial discourse, in which the meaning of the phrase can also be lost, the speech is skated ("ejaculation ... of the spill ... spilling"). It has a rich vocabulary, specific to its school level and at the same time, it tries to gain credibility and to impress, keeping a moderately rhythmic voice. It also has moments in which the intensity of the voice increases, being full of emphasis with a declamatory voice. Thus, he shows that he overestimates the facts reported. The "commanding" neologism perfectly describes the xenopathic delirium experienced by the patient. He uses the passive diathesis and "No one wants", the whole discourse in the area of the secret seeming to say, "Nobody wants me". [8]

\subsubsection{Affectivity}

- parental dependence, knowing himself mentally ill: "what do I do if my parents die" - cage / cell; feels the need to a financial recovery

- a pathology of maternal exacerbation caused perhaps by the symbiosis with it, carried out during an oedipal period with a lack of clarity of feelings towards the mother (her fault or self that cannot protect her): the perspective of the light woman who offers to others men, deceiving his father is antithetical to the victim's perspective before the abusers. Also, when it falls into the category of "light woman" it refers not only to sexual actions, but also to the constant change from one state of mind to another.

- attachment to the mother is generalized to certain women who awaken certain emotional experiences (eg takes on the role of conqueror in the relationship with the interviewer, a "rabbit" affection, is charismatic "you are an Aquarius if I am not mistaken, that I understand well with Leo", try to impress her by exaggerating the related stories)

- flattening of emotions: no real emotional reactions are surprised during the story, he transmits superficiality - coming from the repetitions of the false memories that concern him exaggeratedly

-description of the affective function outlines a maniacal image, but it is not a genuine maniacal one that will contaminate you with his / her experience, it is probably only in the paranoid state of stress developed with the purpose of coping. [9] 
- is suspicious of others, cautious, it opens only after the confidence is gained ("I have a self-esteem over which I am willing to pass only certain people.")

- when asked if he has children, he shows his desire, but at the same time, his lack of responsibility: he mentions the existence of a child of his, from flowers: "I left pregnant a gypsy that my father went to when I told him to give it to him abortion money, and she showed him the baby who was already big"

\subsubsection{Activity}

It presents an attitude of aggression poorly managed when it brings into question the current personal income (450 lei obtained from forced retirement). It manifests an uncontrolled anger for those who pull the strings (eg "this country ruler is my biggest enemy"). The behavior is suspicious, impulsive-unpredictable, bizarre - psychically modified, but we do not estimate the passage to the fact, it completes in the delirium of imagination that cannot reach concrete.

\subsubsection{Motivational system}

Reversal to parents - when it presents the contractual registration in the game, it presents it as a business in which it invests 800 lei for a profit that aims to restore its economic status, thus diminishing part of the dependence on the parents, the financial one. The emotional involvement of the parental bond has left deep wounds that have not closed (it is not suppressed), but still bleed (childhood traumas are evoked, being associated with events from the delirium present).

- Removing the label of mental illness

- Justifying some thoughts

\subsubsection{Awareness of the disease}

It even speaks of the onset of pathological symptoms. He mentions the possibility of an imbalance in the cerebral level that started with the beginning of the sexual life at the age of 18 with the Romanian high school teacher.

The patient is aware that he has problems with memory, these are the ones that cause him concern, because he has not found a resolving process and he does not feel in control, as compared to the mental diagnosis to be denied once the game is won. [9]

He is aware of the superficial disease: he considers himself functional, apt to achieve what he proposes (thought that he constantly feeds through false memories in which he demonstrates his abilities in front of important personalities), but disturbs him in the way which the others relate to (I call him the paranoid schizophrenic label). He does not accept his condition and does not properly integrate what is happening with him.

\section{Conclusions and Recommendations}

Hyper-analyzes the actions and behaviors of other patients, is fascinated by OCD (obsessive compulsive disorder), in which he knows that there is control, develops associations through 
contiguity (ejaculation - to shed - shed), is fascinated by orgies, which he claims to amuse, involving in the confabulatory scenes the doctor with who interacted and perceived as rapists and abusers (the representation being a concrete one in the acts described by the orgy, the patient could easily jump from metaphorically into concrete).

At the end of the interview, the head of the war criminals declares himself, considering that giving up the game would be equivalent to having no discernment: "Everyone wants for me to give up this game, but I have nothing else. I have only enemies and I still have a book to guide me: The woodcutter". With the delusion of the imagination delirium decreases the danger in behavioral acts of the one concerned. [10]

We ask the question to what extent the patient changes the doctors, especially the female doctors, from a particular variety to protect them from the intensity of his aggressive libidinal fixations (because all the speeches regarding the female doctors refer to the ratio of power and rape):

"I was told that if I do not pass the test of time, my mother will die, because she has been prevented by some wood." (The metaphorical leap in concrete and vice versa)

"After the negation, the game lasts longer. I will be an assistant first, then I will become a doctor and move to the other side of the barricade. I was kind of God. I'm guilty and everyone wants to blame me. I have two chances to escape and then the end of the game will be: to be an anchor like my father and to die drowned or to be Jesus and to put the company in the spotlight. Only then can the game end and only I will win. Didn't Basescu play chess to become the Mayor of the capital?" Behind the delirium of Florida, built to hide the secret of the disease, there is depression and anguish related to the fact that even he realized he was sick. Magnitude is of immature type, sustained by magic, by the experience of being subjected to tests that must be overcome and predictions to be fulfilled. The persecution is identified with notes of bonhomie and satisfaction that curb the grandeur, the illusory experience that the characters in the entourage do not march to his erotomania, which makes him construct imaginative delusions focused on rapes. The issue of secrecy is related to the place of control that is xenopathic in paranoid schizophrenia, so that the patient oscillates between experiencing greatness versus experiencing manipulation. Feel the sense of discernment just as our mind feels the sense of secrecy. It hides in neologisms, in cryptomnesia, in fantasies of reduplication. [11]

He uses the passive diathesis and "No one wants", the whole discourse in the area of the secret seeming to say "Nobody wants me". There are phenomena of diffusion of thoughts, but the patient then returns by pointing: "I am the core." All imaginative scenarios are embroidered on pseudoreminiscences and have as their main theme the negation (paradoxically it is not denial !!!).

We find the enormity, referential experiences, ideas of invention and reform, with the particularity of the case:

"I resist with all the medicines you give me and against them!" Under the emphatic affectation, we find the judge, the ambivalence towards the illness and towards the parents, the symbolic significance of remaining locked up in the cage of madness if he risks not winning the game. The disorganization dimension is supported by the cognitive deterioration, by the circumstance and the 
patina of the speech, by the lack of mentalization capacity. As long as there is hope of denial the secret is kept.

What's next? Identification with the aggressor or the savior? As long as the control is xenopathic, the patient can be anyone, a fact that originates in the confusion of roles and illogical constructions. We sometimes identify inadequate affections, such as an emphatic laughter about rape: "If I can't do anything to the mother, I look at how everyone rapes her and just look at her." In this symbolism, the mother is a light woman that floats, and dad an anchor, which if you don't get, you risk dying. The patient has real raptures in his confabulations, failing to act out in the direct register as an antisocial, but builds paranoid scenarios with power factors, SRIs, prosecutors, which he detonates. In a concrete male reality, his impulsive charges are so psychically shifted that he "forgets" to masturbate. In counterpart, fantastic and dreamlike confabulations with large masses of people with severed heads appear. [12]

His plans for invention and reform belong to the court, the secret behind being the depression and risk of suicide. Like any paranoid schizophrenic, he lives superimposed lives and chooses the one that suits him at the right time, with prognostic mnesic disorders making it easy to slip between planes. His speech leads to trace elements, to phosphorus, calcium and chlorine, as all schizophrenics do in the attempt to hyper-analyze and touch the essence. The use of the projection mechanism and the psychotic productivity are related to schizophrenia. From a psychodynamic perspective, in his exaggerated sadism we find the anal dimension, and in the perpetual attempt to obtain the negation of the diagnosis, the hysterical seduction. [13]

Despite the rich ideational flow, the sense is lost, the thoughts are disorganized, we do not find emotion and empathy, but only metaphors. Its secret lies in the growth of the imaginary and the growth of this type of discourse in which dreams - with and without meaning - are integrated in reality to reduce their degree of danger. We are talking about a delirium of imagination that includes reference, persecution and prejudice. An oil delirium, in which characters are still involved, the mother being the main object of the persecution. At the limit, the patient is merged with the mother. The "political" delirium slips into a Blue Whale type, with no regrets. Erotic pleasure is one in the sadistic and masochistic register, where at the limit we find the ghost of incest and homosexual experiences. Anchor stops him from suicide.

The fixtures are aggressively and violently themed with reference to incest. His image struggles between formerly ill and fragile child, successful adult, policeman and adult wreck with paranoid schizophrenia. Maybe sometime, given the childhood illness, my mother has hindered her step by step to become a healthy adult (see woodcutter's metaphor), which is also why the patient symbolically rapes her. He plays at all or nothing, there are no differences in shades between Beware of the donkey (children's game), Blue whale and the Russian roulette (games for real men). The patient himself sees either the garbage man who deserves the lethal injection, or Jesus capable of winning the game. His thinking is dominated by the conflict between the concrete and the abstract, the secret of the paranoid being the emphatic ability to transform his powerlessness into "I am invincible!", because for the paranoid "at first it was the word". 


\section{References}

[1] Kay J., Tasman A. (2016). Essentials of Psychiatry, Chichester: John Wiley \& Sons Ltd

[2] Crichton, P. (1996). Did Othello have the Othello syndrome. The Journal of Forensic Psychiatry, Volume 7, Issue 1, pp.161-169. doi: 10.1080/09585189608409924

[3] Kataoka H., Sugie K. (2018). Delusional Jealousy (Othello Syndrome) in 67 Patients with Parkinson's Disease. Frontiers in Neurology. 9: 129. doi: 10.3389/fneur.2018.00129

[4] Tasman, A., Kay, J., Lieberman, J.A., First, M.B., Maj, M. (2008). Psychiatry. Third Edition. John Wiley \& Sons, Ltd.

[5] Stahl, S.M. (2005). Essential Psychopharmacology - The Prescriber's Guide, 2nd edition. New York:Cambridge University Press.

[6] Kaplan, H.I., Sadock, B.J. (2015). Synopsis of Psychiatry, 11th edition. Lippincott Williams \& Wilkins Publishing House.

[7] Tellegen, A. (1985). Structures of mood and personality and their relevance to assessing anxiety, with an emphasis on self-report. In A.H. Tuma \& J.D. Maser (Eds.), Anxiety and the anxiety disorders. Hillsdale, NJ: Erlbaum.

[8] Clark, D.A., Beck, A.T., Stewart, B. (1990). Cognitive specificity and positive-negative affectivity: Complementary or contradictory view on anxiety and depression? Journal of Abnormal Psychology. 43.

[9] Clark, L.A., Watson, D. (1991). General affective dispositions in physical and psychological health. In C.R. Snyder \& D.R. Forsyth (Eds.), Handbook of social and clinical psychology: The health perspective. New York: Pergamon Press

[10] Stahl, S.M. (2013). Essential Psychopharmacology - Neuroscientific Basis and Practical Applications, 4th edition. New York:Cambridge University Press.

[11] Shaw, D.S., Hyde, L. W. \& Brennan, L. M. (2012). Early predictors of boy's antisocial trajectories. Development and Psychopathology, 24, 871-888. doi:10.1017/S0954579412000429

[12] Black, D.W. (2015). The Natural History of Antisocial Personality Disorder. Can J Psychiatry. 2015 Jul;60(7):309-14. doi:10.1177/070674371506000703

[13] Werner, K.B., Few, L.R., Bucholz, K.K. (2015). Epidemiology, Comorbidity, and Behavioral Genetics of Antisocial Personality Disorder and Psychopathy. Psychiatr Ann. 2015 Apr;45(4):195199.

*Corresponding author.

E-mail address: simonatrifu @yahoo.com 